\title{
DENGUE HEMORRHAGIC FEVER: AN UNUSUAL CAUSE OF INTRACEREBRAL HEMORRHAGE
}

Pankaj Yadav ${ }^{1}$, Ashutosh Chitnis², Abhay Gursale², Vyankatesh Aironi ${ }^{4}$, Pankaj Chaudhari ${ }^{5}$

\section{HOW TO CITE THIS ARTICLE:}

Pankaj Yadav, Ashutosh Chitnis, Abhay Gursale, Vyankatesh Aironi, Pankaj Chaudhari. "Dengue Hemorrhagic Fever: An Unusual Cause of Intracerebral Hemorrhage". Journal of Evolution of Medical and Dental Sciences 2015; Vol. 4, Issue 59, July 23; Page: 10387-10389, DOI: 10.14260/jemds/2015/1498

\begin{abstract}
Dengue is the most important arboviral disease of humans. An estimated 50 million dengue infections and 500,000 Dengue Hemorrhagic Fever cases occur annually, particularly in south-east Asia, the western Pacific and the Americas.[1] The overall mortality in dengue infection is $1-5 \%$ without treatment and less than $1 \%$ with adequate treatment however severe disease carries a mortality of $26 \% .{ }^{[2],[3]}$ Hemorrhagic complications causing intracerebral hemorrhage is rare but fatal. We report a case of 30 year old male with dengue haemorrhagic fever with intracerebral hemorrhage.
\end{abstract}

KEYWORDS: Dengue hemorrhagic fever (DHF), Intracerebral hemorrhage.

INTRODUCTION: Dengue fever results from infection by any of four serotypes of dengue viruses. Transmission occurs through the bite of infected Aedes mosquitoes, principally Aedes aegypti. Hundreds of thousands of cases of dengue and DHF are reported each year in tropical regions of the Americas, Africa, Asia and Oceania. The characteristic symptoms of dengue are sudden-onset fever, headache (Typically located behind the eyes), muscle and joint pains, and a rash. The alternative name for dengue, "break bone fever", comes from the associated muscle and joint pain,[4],[5] In a small proportion of cases, the disease develops into the life-threatening Dengue hemorrhagic fever (DHF) resulting in bleeding, low levels of blood platelets and blood plasma leakage, or into Dengue shock syndrome (DSS) where dangerously low blood pressure occurs.

CASE REPORT: A 30-year-old male was admitted with high-grade fever since 1 week and generalized weakness since 3 days. Investigations at the time of admission revealed hemoglobin $4.8 \mathrm{~g} / \mathrm{dl}$, platelet count $39,000 / \mathrm{mm} 3$, leucocyte count $3100 / \mathrm{mm} 3$. Erythrocyte sedimentation rate was $89 \mathrm{~mm}$ at the end of 1 hour. Typhoid was negative by slide agglutination test. Peripheral smear for malarial parasite was negative. Dengue specific NS1 antigen was positive. Urine routine and microscopic tests were normal. Blood pressure was normal 130/90mm Hg.

The following day platelet count dropped to $18000 / \mathrm{mm} 3$; whole blood and platelets were transfused.

Other investigations were done; S. Bilirubin $1.5 \mathrm{mg} / \mathrm{dl}$. Bleeding time $4 \mathrm{~min} 20 \mathrm{sec}$ and Clotting time $6 \mathrm{~min} 40 \mathrm{sec}$. Patient was discharged with platelet count 60,000 and $\mathrm{Hb} 10 \mathrm{gm} / \mathrm{dl}$.

Patient came back same day evening in unconscious state with high grade fever, headache and single episode of convulsion. History of head trauma was absent. Glasgow Coma Scale (GCS) score was 5 (E1V1M3) and CT brain was advised. 


\section{CASE REPORT}

\section{Non-Enhanced Computed Tomography Scan Brain Show:}

Fig. 1: Axial CT shows hyperdense intra axial collection in the right parietal lobe with small hypodensities within this collection suggestive of actively bleeding intra cerebral hemorrhage. Extension of this hemorrhage into lateral ventricles which are dilated.

Fig 2: Extension of the hemorrhage into third ventricle which is dilated.

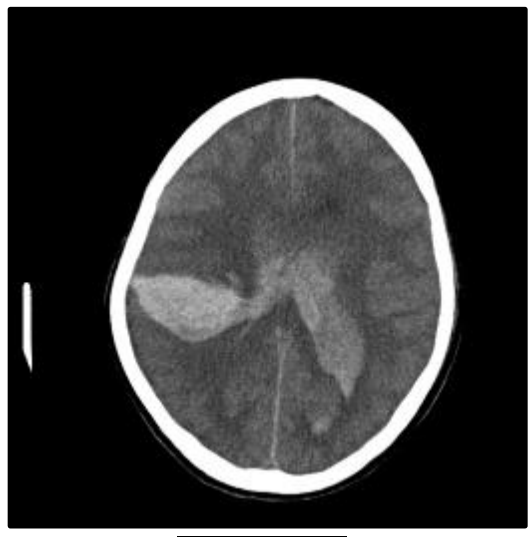

Fig. 1

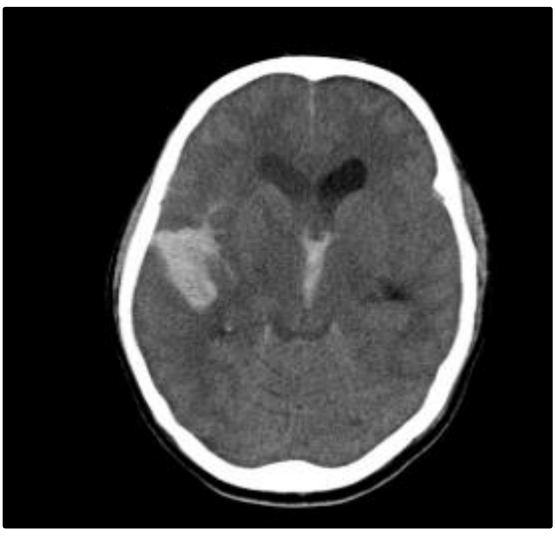

Fig. 2

Fig. 3: Intraventricular hemorrhage into fourth ventricle which is dilated. There is also effacement of suprasellar cistern suggestive of descending tentorial herniation.

Fig. 4: Overall effacement of cortical sulci suggestive of diffuse cerebral edema.

Fig. 5: Hyperdense smearing of interhemispheric fissure suggestive of subarachnoid hemorrhage.

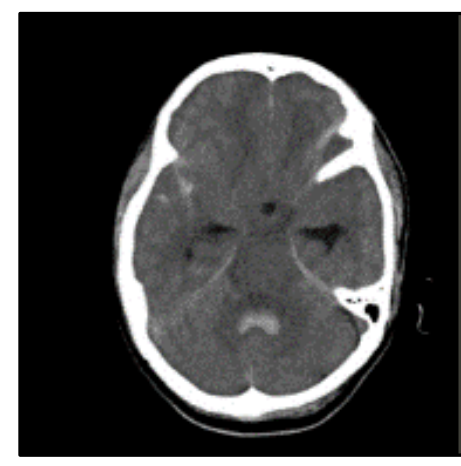

Fig. 3

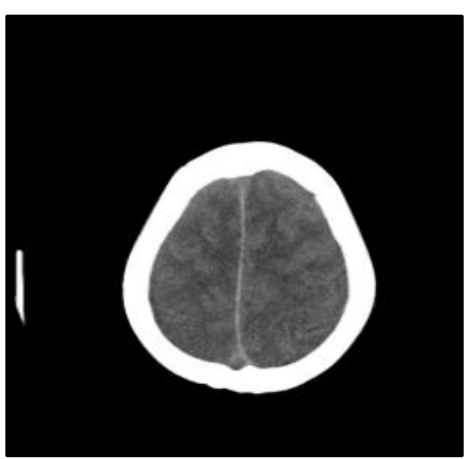

Fig. 4

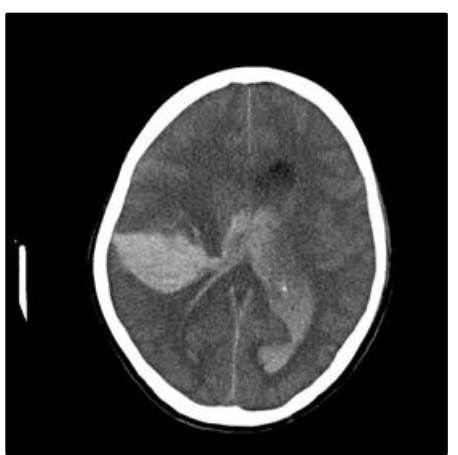

Fig. 5

The patient was transferred in the intensive care unit and was given fluid resuscitation, mechanical ventilation and blood transfusion however despite of all the life saving measures the platelet count fall to $6,000 / \mathrm{mm}^{3}$ and he died.

DISCUSSION: This case further investigates the potentially fatal neurological complication of dengue infection. Therefore, a high index of suspicion is required in patients with short duration of febrile illness with altered sensorium, especially in endemic areas of the disease. Patient with neurological signs in dengue fever should always be investigated by CT scan brain. The findings should not be misinterpreted as toxic encephalopathy. Immediate attention, timely diagnosis and management can thus save life of the patient. 


\section{CASE REPORT}

\section{REFERENCES:}

1. WHO Scientific Working Group on Dengue. Meeting report. [Online-see Related Links], (2000).

2. Ranjit S, Kissoon N. Dengue hemorrhagic fever and shock syndromes. Pediatr Crit Care Med 2011; 12: 90-100. [PUBMED] [FULLTEXT]

3. WHO. Dengue Guidelines for Diagnosis, Treatment, Prevention and Control. 10-11. Geneva: WHO; 2009.

4. Whitehorn J, Farrar J (2010). "Dengue". Br. Med. Bull. 95: 161-73. doi:10.1093/bmb/ldq019. PMID 20616106.

5. Chen LH, Wilson ME (October 2010). "Dengue and chikungunya infections in travelers". Current Opinion in Infectious Diseases 23 (5): 438-44.

doi:10.1097/QCO.0b013e32833c1d16. PMID 20581669.

\section{AUTHORS:}

1. Pankaj Yadav

2. Ashutosh Chitnis

3. Abhay Gursale

4. Vyankatesh Aironi

5. Pankaj Chaudhari

\section{PARTICULARS OF CONTRIBUTORS:}

1. $2^{\text {nd }}$ Year Junior Resident, Department of Radiodiagnosis, MGM Medical College, Kamothe, Navi Mumbai.

2. Associate Professor, Department of Radiodiagnosis, MGM Medical College, Kamothe, Navi Mumbai.

3. Professor, Department of Radiodiagnosis, MGM Medical College, Kamothe, Navi Mumbai.

FINANCIAL OR OTHER COMPETING INTERESTS: None
4. Associate Professor, Department of Radiodiagnosis, MGM Medical College, Kamothe, navi Mumbai.

5. $2^{\text {nd }}$ Year Junior Resident, Department of Radiodiagnosis, MGM Medical College, Kamothe, Navi Mumbai.

\section{NAME ADDRESS EMAIL ID OF THE CORRESPONDING AUTHOR:}

Dr. Pankaj Yadav, Department of Radiodiagnosis, MGM Medical College,

Kamothe, Navi Mumbai-410209.

E-mail: pankajimwatim@gmail.com

Date of Submission: 13/06/2015. Date of Peer Review: 15/06/2015. Date of Acceptance: 13/07/2015. Date of Publishing: 23/07/2015. 